\title{
Qatar's effort for the deployment of Carbon Capture and Storage
}

\author{
Mohammad A.T. Alsheyab \\ Program Manager R\&D -Qatar Foundation and Research Consultant for SIDRA Medicine \\ Received: 16/02/2017, Accepted: 12/10/2017, Available online: 18/10/2017 \\ *to whom all correspondence should be addressed: e-mail: malsheyvab@gmail.com
}

\begin{abstract}
Carbon Capture and Storage (CCS) is an advanced technology that has the technical potential to provide dual advantages: (1) it helps countries maintain their hydrocarbon - driven economic advancement, such as Gulf Corporation Council countries (GCC) and (2) mitigates the negative effects of increasing $\mathrm{CO}_{2}$ emissions. A full system of CCS consists of $\mathrm{CO}_{2}$ separation, compression, transportation, injection into underground reservoirs and long-term monitoring. Qatar is very well aware of the adverse consequences of the rise of $\mathrm{CO}_{2}$ emissions and therefore started investing heavily in Carbon Capture and Storage and took major steps to mitigate the negative impact of $\mathrm{CO}_{2}$. It is believed that CCS would provide a major shift in mitigating the $\mathrm{CO}_{2}$ emissions. This paper will analyze the potential deployment of CCS in Qatar as well as the efforts expended so far in that regard.
\end{abstract}

Keyword: Carbon Capture and Storage, Climate Change, $\mathrm{CO}_{2}$ emissions, Capture technologies.

\section{Introduction}

Carbon is an essential element of all living things; it forms part of the air (atmosphere), water (hydrosphere) and ground (geosphere). It is being recycled between these three spheres and this is known as the carbon cycle. In the atmosphere, carbon is combined with oxygen to form $\mathrm{CO}_{2}$, this molecule used to be steady in the atmosphere until 200 years ago when it started increasing due to the increase of human activities, which currently injects about 33 billion tons of $\mathrm{CO}_{2}$ to the atmosphere every year causing a serious adverse effect on the climate change and global warming.

$\mathrm{CO}_{2}$ is one of the greenhouse gases that traps the energy from the sun and keeps earth at a livable temperature. However the recent increased emissions of $\mathrm{CO}_{2}$ is causing adverse effects on the global warming and climate instabilities which change the weather patterns. This resulted in creating a public concern which led to the establishment of United Nations Framework Convention on Climate Change in 1992, whose objective is to stabilize the greenhouse gases at a level that prevents the human interaction with the climate (Banan and Abbas, 2013). The Energy International Agency studies showed that $\mathrm{CO}_{2}$ emissions in 2050 should be half the emissions of $\mathrm{CO}_{2}$ in 2005 (IEA, 2011).
Many mitigation technologies can be used to reduce the $\mathrm{CO}_{2}$ emissions to atmosphere. These could be categorized into two groups: (1) the relatively low cost technologies, which includes improving energy supply and end-use efficiency; switching from oil and coal to gas where possible; forestation and the use of renewable energy, and (2) more costly mitigation technologies which include carbon capture and storage; nuclear power and large scale renewable energy production.

While the major drawbacks of the first category are the limited impact and their suitability for only short term, the drawbacks of the second category are safety, public acceptance and yet high cost of renewable energy (US DOE, 1990; US DOE, 1997).

Carbon capture and storage was reported to be a promising technology for $\mathrm{CO}_{2}$ mitigation for mid- to long- term (US EIA, 2014).

This paper aims at reviewing the status of carbon capture and storage in Qatar and the efforts Qatar is expending to support scientific research in this area.

\section{Carbon dioxide emissions status in Qatar}

Currently Qatar has an energy based economy as it is the world's third largest dry natural gas producer, estimated in 2012, behind Russia and Iran as seen in Table 1. Qatar is the largest exporter of liquefied natural gas (LNG) in the world and it is home to the world's largest gas-to-liquid (GTL) production plant. This provides a significant portion of the government revenue. The daily production of liquid fluids in 2013 was 1.6 million barrels per day, of which about $45 \%$ is crude oil and 55\% is non-crude oil (UNDP, 2013).

Table 1. Top 10 countries with proved natural gas reserves, 2014

\begin{tabular}{cc}
\hline Country & Trillion Cubic Feet \\
\hline Russia & 1688 \\
\hline Iran & 1193 \\
\hline Qatar & 885 \\
\hline United States & 334 \\
\hline Saudi Arabia & 292 \\
\hline Turkmenistan & 265 \\
\hline United Arab Emirates & 215 \\
\hline Venezuela & 196 \\
\hline Nigeria & 181 \\
\hline Algeria & 159
\end{tabular}


According to the 2012/2013 Human development report published by the United Nations Development Program (UNDP 2013), the Qatari national carbon dioxide estimate is of 68 million tons (MMt) per year in 2008, which estimates amount to approximately 49.1 tons of $\mathrm{CO}_{2}$ per capita. While the Qatari total $\mathrm{CO}_{2}$ emissions is lower than other GCC countries (KSA $=434 \mathrm{MMt} /$ year, UAE $=155.25$ $\mathrm{MMt} /$ year, Kuwait $=77 \mathrm{MMt} /$ year), the estimate amounts of tons of $\mathrm{CO}_{2}$ per capita are much higher than these GCC countries (KSA = 16.3 tons, UAE $=25$ and Kuwait $=30.1$ ) (UNDP, 2013; Qatar National Development Strategy, 2011).

Fuel combusted for energy production accounts for $67 \%$ of $\mathrm{CO}_{2}$ emissions in Qatar, out of this $12 \%$ is attributed to gas flaring and $18 \%$ stems from petrochemicals, water and power industry. The remaining $33 \%$ of the total emissions is attributed to household and commercial users. Globally, Qatar's carbon dioxide emissions are about $0.2 \%$ of the world's total. However Qatar is unfairly classified as the highest per capita emissions in the world. However this indicator is misleading as it uses production-based emissions accounting where large amounts of exported fossil fuels are assigned to Qatar rather than the countries importing and using the product .This approach puts Qatar as number one in the world as carbon dioxide emitter per capita being a small country and main producer of fossil fuels. This ranking would be changed if it was measured on consumption basis (CDIAC, 2012).

In 1996 Qatar ratified the United Nations Framework Convention on Climate Change (UNFCCC) and in 2005 ratified the Kyoto protocol. Although Qatar's $\mathrm{CO}_{2}$ emissions continued to increase, the per capita emissions was reducing as seen in Figure 1 (WB, 2012; Qatar General Secretariat for development planning 2012).

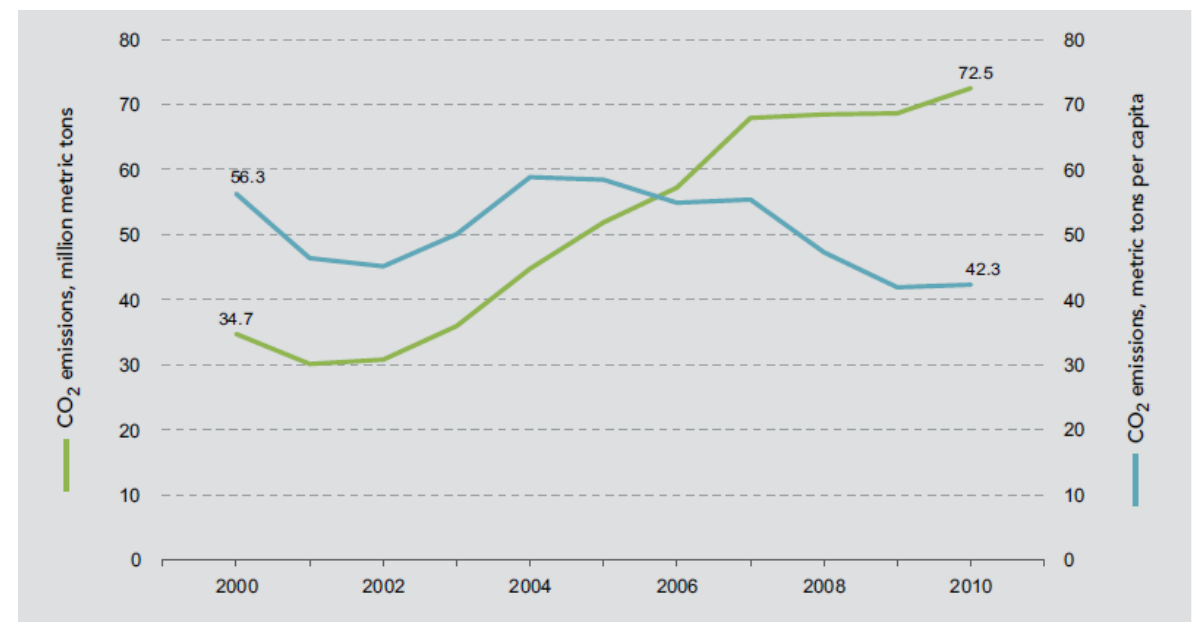

Figure 1. Qatar's continued increase of $\mathrm{CO}_{2}$ emissions and declination on per capita basis (WB, 2012; Qatar General Secretariat for development planning 2012)

\section{Expected adverse Impacts of Climate Change on Qatar}

Qatar is highly vulnerable to various adverse impacts that may result from climate change; these threats are summarized in the following points [CDIAC, 2012; WB 2011).

- If the temperature rise is accompanied with a rainfall decrease, there will be moisture losses from Qatar's water-stressed land.

- If a moisture loss happens then further desertification and increased water demand will take place.

- Increased water demand will require more production of desalinated water and consequently more energy consumption and $\mathrm{CO}_{2}$ emissions.

- Increased temperatures will increase the degradation of air quality and adversely affect the human health.

- Qatar is one of three Arabian Gulf countries (along with Bahrain and Kuwait) and among the 10 countries in the world that would be affected by rise in sea level. This would damage the coastline and the marine life.

- Having shallow marine depths, Qatar's ecosystems will be adversely affected by climate change. This will cause negative impacts on mangroves, coral reefs and sea grass beds.

\section{Qatar's major steps to mitigate $\mathrm{CO}_{2}$ emissions:}

Qatar is very well aware of the adverse consequences of the rise of $\mathrm{CO}_{2}$ emissions, especially being highly vulnerable to the changes that may result from climate change such as: (1) the rise in sea level which would damage the coastline and the marine life, (2) Increase of water demand and salinity in groundwater and (3) weather extremes which could result in heavy local flooding and sand storms [9]. Some of these negative consequences are already causing a decrease of rainfall and an average increase of local atmospheric temperature by $1.2 \mathrm{C}$. Therefore Qatar has taken major steps to mitigate the $\mathrm{CO}_{2}$ emissions summarized as follows:

- $\quad$ Taking steps to reduce carbon emissions including legislation to limit emissions, Cleaner technologies 
and adopting innovative research on carbon capture and storage.

- In 2007 Qatar introduced its first United Nation Framework Convention on climate change Clean Development Mechanism, Al-Shaheen Oil Field Gas Recovery and Utilization project, which reduced flaring by about $80 \%$.

- Designing facilities to achieve zero gas flaring at Al-Karkara field by 2011 , by injecting excess sour gas back into the reservoir.

- Active role of Qatar's leading energy companies to mitigate $\mathrm{CO}_{2}$ emissions. For example, RasGas operated the regions first acid injection (AGI) scheme that stores $\mathrm{CO}_{2}$ and $\mathrm{H}_{2} \mathrm{~S}$ generated from production process, resulting in substantial reduction in $\mathrm{CO}_{2}$ emissions.
- In 2008 Qatar Petroleum and Exxon Mobil made a breakthrough resulted from their research into liquefied natural gas (LNG) carrier design and size, enabling $80 \%$ more LNG transportation than the current technology which reduced substantially the energy consumption.

- The operators of the Al-Shaheen oil field, Qatar Petroleum and Maersk Oil, partnered to reduce the flare gas in a percentage that nowadays provide one-third of Qatar's electricity and resulted in a reduction of 2.5 million tons of $\mathrm{CO}_{2}$ per year (BP, 2013).

\section{Current scenarios of Carbon Capture Technologies}

Three main technologies have been developed for $\mathrm{CO}_{2}$ capture and storage. These include:

1. Post-process capture: the process of this technology is summarized in figure 2. The flue gas is produced at low pressure with $\mathrm{CO}_{2}$ content varies from $4-8$ vol. \% and goes through a $\mathrm{CO}_{2}$ separator and then compressor to liquefy $\mathrm{CO}_{2}$ before transportation.

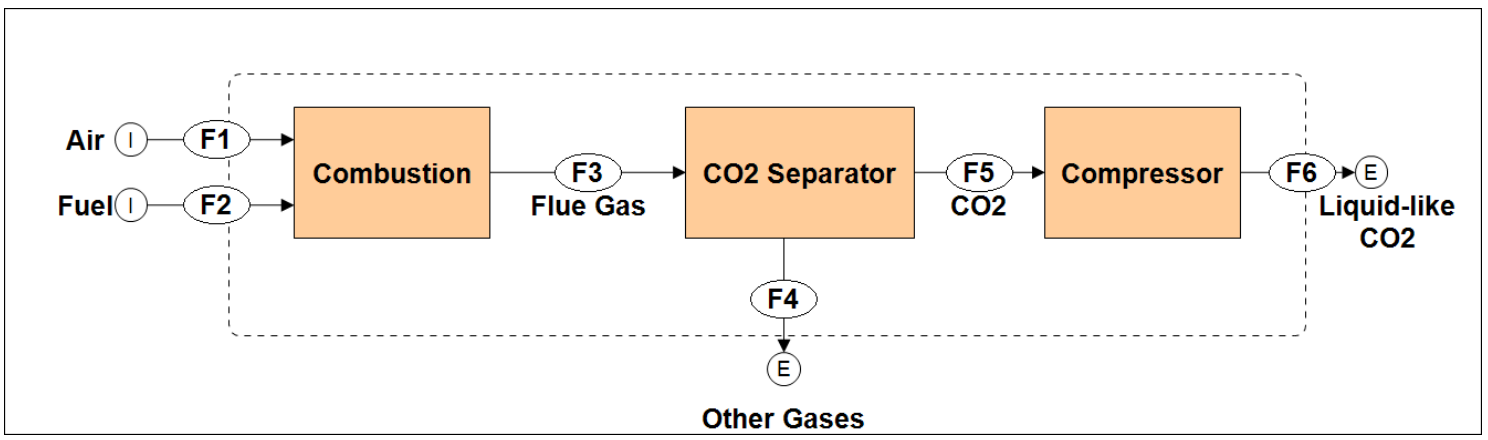

Figure 2. Post -combustion capture technology of $\mathrm{CO}_{2}$

2. Pre-combustion process: Figure 3 explains the process flow diagram. The process basically consists of an air separated unit to produce oxygen and then a fuel gasifier that produces syngas $\left(\mathrm{H}_{2}\right.$ and $\left.\mathrm{CO}\right)$ which goes through a shift reaction to produce syngas $\left(\mathrm{H}_{2}+\mathrm{CO}_{2}\right)$ where $\mathrm{CO}_{2}$ content varies from 15-40 vol.\%.

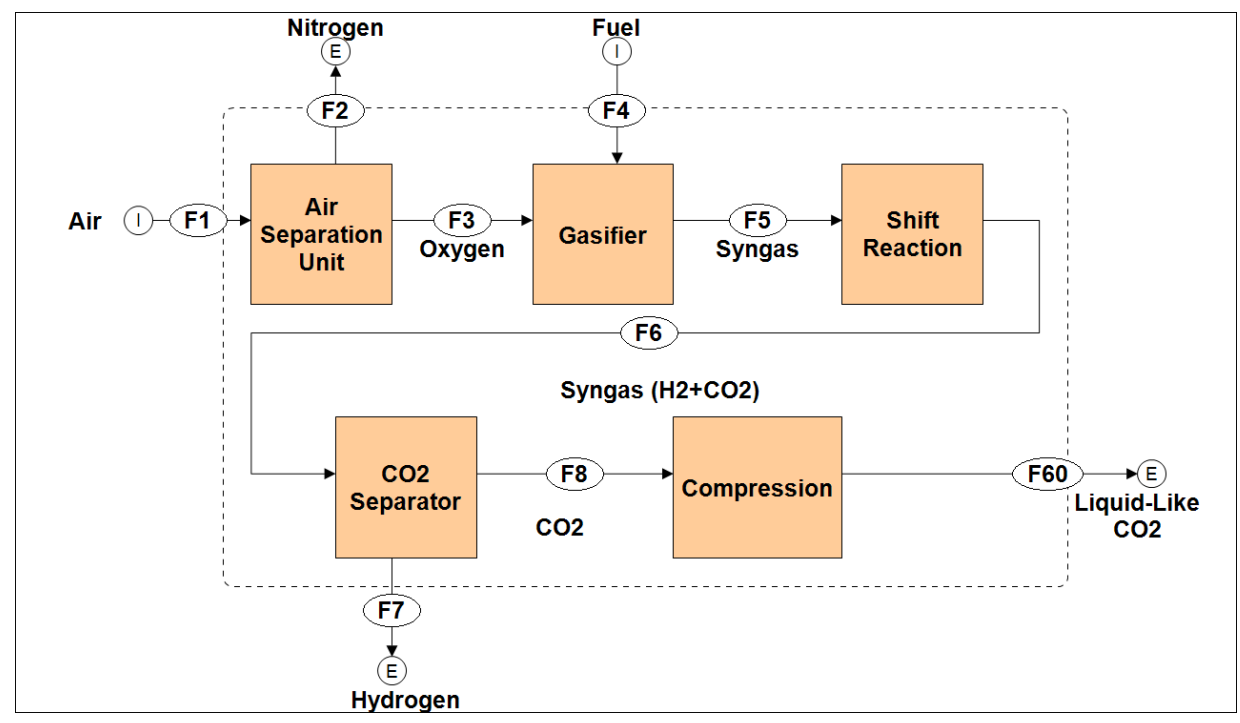

Figure 3. Pre-Combustion capture technology of $\mathrm{CO}_{2}$ 
3. Oxyfuel-combustion process: Figure 4 below shows the process flow diagram consisting of oxygen separation from air to be used in fuel combustion to produce $\mathrm{CO}_{2}$-rich flue gas which goes through a $\mathrm{CO}_{2}$ separator producing a high concentration $\mathrm{CO}_{2}$ which is then compressed to produce liquid-like $\mathrm{CO}_{2}$ ready for transportation.

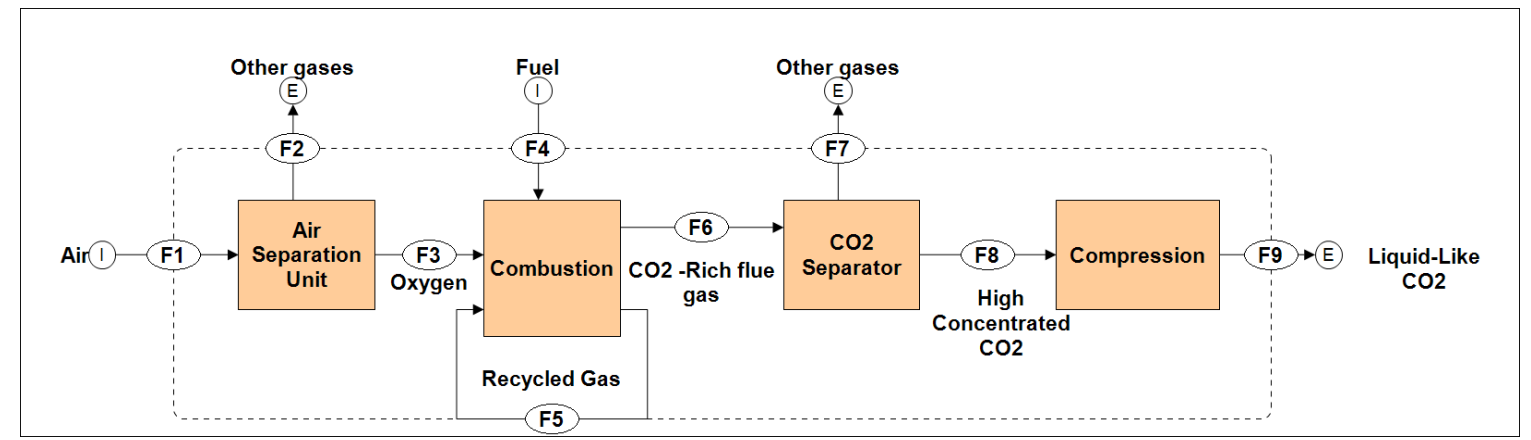

Figure 4. Oxyfuel Capture technology of $\mathrm{CO}_{2}$

\section{Carbon Capture Storage status in Qatar}

Having the third largest natural gas reserves and the $13^{\text {th }}$ largest oil reserves in the world, Qatar relies entirely on oil and natural gas for its energy needs. $96.5 \%$ of GHG are attributed to energy sector, where almost $50 \%$ of energyrelated emissions come from electricity and heat production. The energy consumption has increased $4.5 \%$ between 2011 and 2012 in the GCC region (Kinninmont, 2010) and it is expected to be double current levels by 2020 (U.S. EIA, 2013). Consequently, this results in continuous increasing of GHG emissions (Meltzer et al., 2014].

Carbon Capture and Storage or sequestration is a technology that aims to reduce the $\mathrm{CO}_{2}$ content in the flue gases of power stations and industrial installations and store it safely to prevent it entering the atmosphere. The use of CCS in Qatar has many advantages which can be summarized as follows (Natural Gas Information, 2010)

- $\quad$ CCS has the potential to reduce $\mathrm{CO}_{2}$ emissions while still allowing extensive use of fossil fuels and natural gas.

- $\quad$ The potential of combining CCS with enhanced oil recovery (EOR) and enhanced gas recovery (EGR) frees up valuable volume of hydrocarbons and helps make CCS economically viable.

- The potential of developing a commercial CCS operation in Qatar would be an important step towards demonstrating its feasibility and would put Qatar at the forefront of developing a climate change technology that could be utilized globally.

- The potential use of CCS in industrial processes, especially that Qatar is home to the world's largest GTL plant and is the world's biggest producer of LNG (Al-Kuwari, 2012)

On the other hand CCS is still unproven commercially and the environmental impact and financial risks are still uncertain. For the case of Qatar, there is an uncertainty about the economic return of the commercialization for CCS from natural gas power generation, as natural gas generation is $50 \%$ less carbon intensive than that of coal and if a carbon price is considered to provide incentive for capture, then the economic returns of carbon capture will be lower.

Qatar has taken the following steps towards the deployment of CCS:

- Qatar is investing heavily in carbon capture and Storage. The Qatar Carbonates and Carbon Storage Research Centre was established to strengthen Qatar's engineering talent and expertise and expand research capacity in carbon capture and storage (CCS) and cleaner fossil fuels, involving over 40 academic staff, postdoctoral researchers and PhD students. It is a 10-year program of $\$ 70 \mathrm{M}$ budget, hosted at the Imperial College London in the United Kingdom. It aims at combining the local knowledge and expertise of Qatar and the research strengths of Imperial College London, through its Energy Futures Lab, to investigate the key challenges in the exploitation of carbonate reservoirs( Ebinger et al., 2011)

- Also the Qatar Foundation funded 130 grants in environment and energy research totaling $\$ 118 \mathrm{M}$ from $2007-2010$, of which $\$ 9.3 \mathrm{M}$ were funded on carbon capture and storage (Al-Kuwari, 2012).

- Qatar has deployed the injection of $\mathrm{CO}_{2}$ captured from its Pearl GTL plant into the Dukhan oilfield, where production dropped from 350,000 barrels/day in 2003 to 250,000 barrels/day at the end of 2008 (Benamor and Aroussi, 2013).

- The announcement of the release of carbon capture and management Road Map by Qatar University's Gas processing Centre (GPC) in 2012 (International Energy Agency, 2013).

- In 2012, the Qatar fuel Additives Company (QAFAC) ordered a large-scale $\mathrm{CO}_{2}$ recovery plant from Mitsubishi Heavy Industries with plans for installation within its methanol production plant by autumn 2014 (Al-Kuwari, 2012).

- Also Qatar has provided a basic regulatory framework to enable work in CCS. This falls under one of the laws that states "Counteract the effects of pollution in its various forms", and prevent damage as well as instant and long term 
environmental effects of construction, industrial, agricultural and economical activities (Al-Kuwari, 2012).

\section{Conclusions}

- Qatar has a good opportunity in developing an effective system for CCS in LNG production; that would allow exporting the expertise to other nations moving towards natural gas-fired power generation or LNG production in a carbon constrained world.

- Qatar's efforts and initiatives to date are projectoriented and may be it is time to scale it to commercialized level.

- Although the Gas Processing Centre has taken important steps in mapping CCS storage sites in Qatar, further efforts are needed to fill the remaining gaps (International Energy Agency, 2013)

- Although Qatar has already provided a regulatory framework for the capture and storage for EOR and EGR, conducting a thorough environmental assessment of CCS site for long- term storage and questions of liability in the event of leakage, is still needed.

- Qatar should bring in the best available practices on CCS projects from other countries to help Qatar to go the best way forward on CCS.

- Qatar should take a proactive approach in international forums such as the UNFCCC's discussions, Carbon Sequestration Leadership Forum and Global CCS Institute to build expertise, develop CCS capacity, develop specific CCS technologies and commercialize these technologies for use in other countries.

- Qatar should also consider supporting the efforts to price carbon regionally and globally to improve the economic viability of CCS.

\section{References}

Al-Kuwari H. (2012), Memorandum to the Gulf Organization for Research and Development on the Qatar Carbonates and Carbon Storage Research Centre.

Banan Z. and Abbas M. (2013), Carbon Capture \& Storage Deployment in Iran, Energy Procedia, 37, 7492 - 7501.

Benamor A. and and Aroussi A. (2013) Towards a Technology Roadmap for Carbon Capture and Management for Qatar, International Journal of Biological, Ecological and Environmental Sciences (IJBEES), 2(3).

BP, (2013), Statistical Review of World Energy.

CDIAC (Carbon Dioxide Information Analysis Center), (2012), Preliminary 2009 and 2010 global and national estimates of carbonemissions file of CDIAC, US Government. [http://cdiac.ornl.gov/trends/emis/prelim_2009_2010_estim ates.html]

Ebinger Ch., Huktman N., Massy K. and Avasarala G. (2011), Options for low-carbon development in countries of the gulf cooperation council, Published by: Brookings Energy security initiatives

IEA, (2011), Carbon Capture and Storage - Legal and Regulatory Review", Paris, France: International Energy Agency.
International Energy Agency, (2013), Technology Roadmap: Carbon Capture and Storage.

Kinninmont, (2010), The GCC in 2020: Resources for the Future.

Meltzer J., Hultman N. and Langley C. (2014), Low-carbon energy transitions in Qatar and the gulf cooperation council region, Global Economy and Development at the Brookings.

Natural Gas Information, (2010), International Energy Agency, pg. 93.

Qatar General Secretariat for development planning, (2012), Qatar's commitment to sustainable development.

Qatar National Development Strategy 2011 2016, (2011), Towards Qatar National Vision 2030.

U.S Energy Information Administration, (2014), Full report on Qatar January 30.

U.S. EIA, (2013), Country Analysis Briefs: Qatar.

UNDP, (2013), http://hdr.undp.org/sites/default/files/reports/14/hdr2013_ en_complete.pdf

US DOE, (1990), The Potential of Renewable Energy An Interlaboratory White Paper, DE 90000322.

US DOE, (1997), $\mathrm{CO}_{2}$ Capture, Reuse, and Storage Technologies for Mitigating Global Climate Change White Paper, DE-AF2296 PC01257.

WB (World Bank) 2012b. (2012), World Development Indicators and Global Development Finance database, [http://data.worldbank.org].

World Bank, (2011), Qatari Gas Flaring Reduction Project Highlighted in Award-Winning Short Video, web page, As of October 23, 2012: http://go.worldbank.org/KYO1KLN8Q0 